\title{
Status and touching behavior
}

\author{
ALVIN G. GOLDSTEIN and JUDY JEFFORDS \\ University of Missouri, Columbia, Missouri 65211
}

\begin{abstract}
Frequency of intentional touching between legislators differing in political status was observed and recorded during legislative sessions on the floor of a Midwestern state's house of representatives. On the basis of objective and subjective criteria of status rank, younger, lower status individuals were found to be more likely to initiate touching of a higher status conversational partner. These results are not consistent with implications of an earlier observational study of touching behavior. Reasons for the lack of agreement are offered.
\end{abstract}

In the extensive literature on nonverbal communication (e.g., Duncan, 1969; Harper, Wiens, \& Matarazzo, 1978; Key, 1975, 1977), including investigations by anthropologists, ethologists, sociologists, and psychologists, touching behavior has been almost totally ignored. Kauffman (1971), in a review and critique of the work on "tacesics," the study of touch, observed that "of all the proxemic variables, tactile experience has been most neglected by investigators" (p. 150). Several years later, Weitz (1974, p. 203) echoed Kauffman's lament. The present report describes a study of the relation of touching behavior to power status in a controlled field situation, the lower house of the legislature in a Midwestern state.

In a recent article, Henley (1973) described the results of a study of touching behavior based on data obtained by naturalistic observation. She found, in support of her hypothesis, that "high-status" individuals more often touched their lower status partners than the reverse. Social status was determined by employing observable but potentially unreliable indexes of social rank: apparent age, sex, and estimated socioeconomic status.

The validity and generalizability of this claim depends on the extent to which status is reliably expressed in a variety of social situations. For example, although men and women may, in fact, differ in status in American society, there are other non-status-related reasons for a member of one sex more frequently to touch a member of the other sex. Similarly, older age may be thought to confer higher status (although it is an arguable assumption), but in any randomly occurring public encounter, other subtle and at the same time more powerful factors could contribute to, or even determine, the "touching" outcome. In short, controlled observation of touching behavior occurring outside the laboratory requires relatively unambiguous measures of interpersonal status as a prerequisite to successful inter-

June Chance's comments on an earlier draft of this paper are gratefully acknowledged. Reprint requests should be sent to Alvin G. Goldstein, Psychology Department, 210 McAlester Hall, University of Missouri, Columbia, Missouri 65211. pretation of the results. More important, generalizations about age, sex, or even skin color as status variables are relatively meaningless. Status cannot be inferred independently of social context. For example, age alone is not a status variable. In some social contexts, older age implies higher status, but in other contexts (e.g., nursing homes), advanced age implies low status.

An ideal social situation in which to study touching behavior as a function of social status would permit observers unobtrusively to view freely interacting individuals who visibly differ in relative status by virtue of their unique roles in a power-oriented institution. Conditions that closely approximate this ideal can be found in legislative bodies. Legislators meet together in public view in a physically constrained area, such as the floor of the house or senate chamber. Members can be identified readily by name, biographical data are available for each member, and most important, members differ in status as a consequence of several easily determined facts, such as length of service, political affiliation, position(s) held, area of state represented, and committee membership. Also of critical importance for a study of touching behavior as a function of status differences is the fact that legislators are quite sensitive to power relationships; in a real sense, these relationships are their primary business. This sensitivity means that members are aware of status relationships in their interactions with each other on the floor of a house or senate chamber.

\section{METHOD}

Touching behavior between legislators was recorded by two observers (the second author and a male assistant) located in the gallery of the state house of representatives. ${ }^{1}$ Touching behavior included for analysis was limited to intentional touches of one individual by another. Examples of touching behavior included in the final analysis are the following: putting an arm around a person's shoulder and placing one or both hands on another person's arm, chest, or shoulder. Handshakes were not considered to be examples of touching behavior and were excluded from analysis. The touching behavior almost always took place in the context of face-to-face conversation. Despite the fact that the legislature was in session during the periods of observation, legislators moved around the room, socializing and talking, even during the time other legislators were speaking 
over the public address system, defending or attacking a bill or proposed legislation.

For each instance of touching, the identities of both the initiator and receiver of the touch were recorded. Either the names of the legislators were known to the observers or the names were obtained from the doorman (who knew the name of every representative.) All tabulated touching behavior took place on the floor of the house of representatives chamber. All behavior was between male legislators; reliable data on women could not be obtained because of the small number of women legislators. Data were collected during approximately $30 \mathrm{~h}$ of observation.

A variety of sources of information was used to determine status after the observations were recorded. In political institutions, one sign of status is traditional: committee membership. Another sign of status is standing within the committee. For example, chairs of influential committees enjoy high status within the political system. From biographical facts, available from public sources, additional material about each legislator in the sample was obtained. These data included chronological age number of years of service in government, prior committee assignments, and prior chairmanships held. By using all of this information for each pair of legislators engaged in touching behavior, a tentative judgment of relative status was made by one of the authors (J.J.), who was familiar with legislative committee structure. Informal confirmation of these judgments was obtained from several legislators. Consensual agreement was almost always obtained. It was clearly the case that legislators have little difficulty discerning status differences among their colleagues. Data involving questionable status relationships were not included in the analysis reported here.

Some people frequently initiate touching; others rarely touch another person. To control for the effect of this assumed individual difference in touching behavior on the outcome of this study, only one observation of touching (the first observed in every case) was recorded for each legislator included in the present sample (i.e., a toucher's response was scored once even though he was observed touching on other occasions) Touching behavior involving the governor was observed and recorded, but the data were not included in the computational analysis.

\section{RESULTS AND DISCUSSION}

A total of 156 incidents of touching behavior were recorded, and 146 were analyzed. Observations were deleted from the statistical analysis because the status relationship between the pairs of men was indeterminate or because they were too similar in chronological age (i.e., differing by less than 5 years). Although a small number of interactions involved black legislators, too few observations were collected to warrant separate analysis.

Table 1 presents the data categorized by toucher's relative age and relative status. If status alone is considered, the 146 incidents could be expected by chance alone to have been initiated by higher status individuals in about $50 \%$ of the interactions (73 incidents) and lower status individuals in the remaining half of the interactions. The observed frequencies, 62 and 84 , yielded a chi-square value of $3.3(\mathrm{p}=.07)$. Thus, legislators who initiate touching are most likely to be of lower status than are the house members they touch, but the evidence for this conclusion is relatively weak. If age alone is examined, Table 1 shows that the 146
Table 1

Frequency of Touching: Age Relationship and Status Relationship Between Toucher and Person Touched

\begin{tabular}{cccc}
\hline \multirow{2}{*}{$\begin{array}{c}\text { Toucher's Age Rela- } \\
\text { tive to Touchee's }\end{array}$} & \multicolumn{4}{c}{ Toucher's Status Relative to Touchee's } \\
\cline { 2 - 4 } & Higher & Lower & Total \\
\hline Younger & 23 & 48 & 71 \\
Older & 39 & 36 & 75 \\
Total & 62 & 84 & 146 \\
\hline
\end{tabular}

observations split almost equally (71 vs. 75 ) between legislators who touched older colleagues and those who touched younger colleagues $\left(\chi^{2}=.06\right)$, a finding that clearly eliminates age as an important factor in touching behavior under the conditions of this study. (Age, however, was broadly represented in the sample of men included in the analysis.)

When age and status are considered jointly, it is clear that among legislators the younger, lower status individual is more likely to be the initiator of touching behavior (chi-square test of independence $=5.7, .02>p>.01$ ) . The observed relationship between status and touching was given added support by touching behavior involving the governor. At no time was the governor seen to touch another person, but he was frequently touched by others.

Results of this study are not consistent with Henley's (1973) conclusions. She reported that higher status persons appear to have touch "privilege" over lower status persons (Henley, 1973, p. 93). In contrast, the present study demonstrates that in a dyadic relationship, when the two individuals differ in status, the higher status person is less likely to initiate touching than is the lower status person. At least three reasons for the discrepancy in outcomes deserve comment. First, Henley's subjects, in contrast to the legislators in the present study, were ordinary citizens literally walking on city streets and eating in public restaurants. Second, touching behavior was observed in commonplace situations in Henley's study, whereas the legislators in this study were observed as they interacted in a unique setting. The third reason for the discrepant findings may be found in the precision of the status measure itself. Henley inferred status differences between touchers and touchees solely on the basis of visible differences in their dress, estimated age, sex, and other similar superficial signs. These signs were accepted as the only evidence of status rank. Relative status of the individuals involved in touching behavior in our study was based on the structure of the state political system and on judgments of status made by members of the legislature, in addition to factual information about present and past legislative committee membership, age, tenure within the system, and so on. In short, both investigations employed relatively crude measures of status, but our measures involved some overlapping safety features and also included subjective judgments by people familiar with 
the status system itself. Henley's measure lacked these safeguards.

This study tested the generality of Henley's (1973) major finding, namely, that higher status individuals are more likely to touch lower status people. Our results imply that higher status individuals, in at least one social institution, are less rather than more likely to intentionally touch a lower status companion. This finding draws attention to the importance of the context within which touching behavior occurs. Status is not the most important factor in determining who touches whom.

\section{REFERENCES}

Duncan, S. Nonverbal communication. Psychological Bulletin, $1969,72,118-137$.

Harper, R. G., Wiens, A. N., \& Matarazzo, J. D. Nonverbal communication: The state of the art. New York: Wiley, 1978.

Henley, N. M. Status and sex: Some touching observations. Bulletin of the Psychonomic Society, 1973, 2, 91-93.
KEY, M. R. Paralanguage and kinesics. Metuchen, N.J: Scarecrow Press, 1975.

$\mathrm{KEY}, \mathrm{M}$. R. Nonverbal communication: $A$ research guide and bibliography. Metuchin, N.J: Scarecrow Press, 1977.

Kauffman, L. E. Tacesics, the study of touch: A model for proxemic analysis. Semiotica, 1971, 4, 149-161.

Wietz, S. Nonverbal communication. New York: Oxford University Press, 1974.

\section{NOTE}

1. One of the observers was a legislative intern during the time this study was conducted. As part of the internship, interactions with legislators and their office staffs were routine. This unique situation provided the observer with a convenient way to become familiar with many state legislators, in addition to providing contact with other individuals knowledgeable about the status of legislators. The second observer was unaware of the results of previous research on touching behavior and had not been informed of the purpose of the study.

(Received for publication December 22, 1980.) 